\title{
Bildhandlingar
}

\section{Att skapa mening med Titusbågen}

Mårten Snickare

Vad har en konstvetare för glädje av språkfilosofen J. L. Austin och hans tankar om det performativa? Han var ju helt inriktad på det talade språket eller, med ett mer precist uttryck, talhandlingar. ${ }^{.}$Bilder, byggnader, föremål och de andra visuella och materiella fenomen som utgör konstvetenskapens studieobjekt har ingen plats i hans teori. Eller kanske har de det? Vid en noggrann läsning av Austins föreläsningar upptäcker man att flera av de performativa talhandlingar som han diskuterar involverar även icke-språkliga tecken och föremål. Låt oss se närmare på ett exempel, nämligen rättsskipningen. Domarens ord "Jag dömer dig till tio års fängelse" uppfyller alla krav på en performativ talhandling. Genom orden förvandlas den misstänkta till en dömd brottsling. Ett nytt faktum har etablerats i världen. Men det räcker inte med bara orden, påpekar Austin. Det är också väsentligt att de inblandade befinner sig på rätt plats, det vill säga i rättssalen, och att domaren som uttalar orden bär de rätta ämbetskläderna och sitter i sin bestämda stol. ${ }^{2}$ Just stolens betydelse framgår faktiskt av etablerat språkbruk: på engelska säger man om någon som utnämnts till domare att han eller hon har blivit "raised to the bench" och på

Hur du refererar till det här kapitlet:

Snickare, M. 20I7. Bildhandlingar: Att skapa mening med Titusbågen. I Hayden, M. H. and Snickare, M. (red.) Performativitet: Teoretiska tillämpningar $i$ konstvetenskap: I. Pp. I-I6. Stockholm: Stockholm University Press. DOI: https://doi.org/IO.I6993/bal.b. License: CC-BY 4.0 
svenska har stolen fått ge namn åt hela institutionen: domstol.

Här antyds en väg att förstå konstverk, byggnader och föremål i termer av performativa handlingar. Domstolslokalen, kläderna och möblerna, det vill säga rum och föremål som är en förutsättning för den performativa handlingen att döma ut ett straff, är ju samtidigt rum och föremål som hör hemma i konstvetenskapliga objektkategorier som arkitektur, hantverk och design. Härifrån är det lätt att dra paralleller till andra konstvetenskapliga objekt och deras betydelse för genomförandet av performativa handlingar: kronan som sätts på kungens eller drottningens huvud vid en kröning; kyrkointeriören, dess målningar och skulpturer som under gudstjänsten samspelar med musik och talhandlingar; eller triumfbågen som uppförs i samband med en furstes eller härförares triumftåg. Vid närmare eftertanke framstår det här som en väsentlig aspekt av konstvetenskapliga studieobjekt. En stor mängd av de bilder, byggnader och föremål som en konstvetare studerar har skapats för, och brukats i, olika performativa situationer. Istället för talhandlingar skulle vi som konstvetare kunna tala om performativa bildhandlingar, syftande på de handlingar där olika slags bilder, föremål och arkitektoniska rum kan vara minst lika väsentliga för den performativa effekten som de uttalade orden. ${ }^{3}$

I det här kapitlet vill jag visa hur ett konstvetenskapligt studieobjekt kan förstås i termer av performativa bildhandlingar och vilka aspekter av objektet man då får syn på. Exemplet jag valt är Titusbågen, en antik triumfbåge som spänner över 
Via Sacra, huvudgatan i antikens Rom, i den sydöstra delen av Forum Romanum (bild I). Som ett av de mest välbevarade monumenten från den romerska kejsartiden är Titusbågen sedan länge inskriven i den västerländska konsthistoriens kanon. Sedan renässansen har den varit ett viktigt besöksmål för Romresenärer; den har avbildats av tongivande konstnärer som Canaletto (I697-I768), Giovanni Battista Piranesi (I720-I778) och William Turner (I775-I 85I); i konst- och arkitekturhistoriska översiktsverk har den lyfts fram som exempel på kejsartidens arkitektur i allmänhet och den så kalllade kompositaordningen i synnerhet. ${ }^{4}$ Titusbågen har också tjänat som förebild för en rad senare triumfbågar ända fram till Arc de Triomphe i Paris från I 80o-talets början och Washington Square Arch i New York från I 8oo-talets slut. Till och med India Gate i New Delhi, rest av den brittiska kolonialmakten I93 I, kan stilistiskt härledas till Titusbågen. Även i restaureringshistorien har Titusbågen en viktig plats: restaureringen på I 820-talet, under ledning av arkitekten Giuseppe Valadier, brukar lyftas fram som ett av de tidigaste exemplen på modern byggnadsrestaurering. ${ }^{5}$

Titusbågen kan alltså beskrivas som ett paradigmatiskt konstvetenskapligt studieobjekt och den har varit föremål för stilhistoriska, ikonografiska och byggnadstekniska analyser och tolkningar. Men om vi här väljer att betrakta Titusbågen som en performativ bildhandling, vad blir då synligt? Till att börja med att den hänger samman med fältherren Titus triumfatoriska återkomst till imperiets huvudstad Rom efter erövringen och skövlandet av 


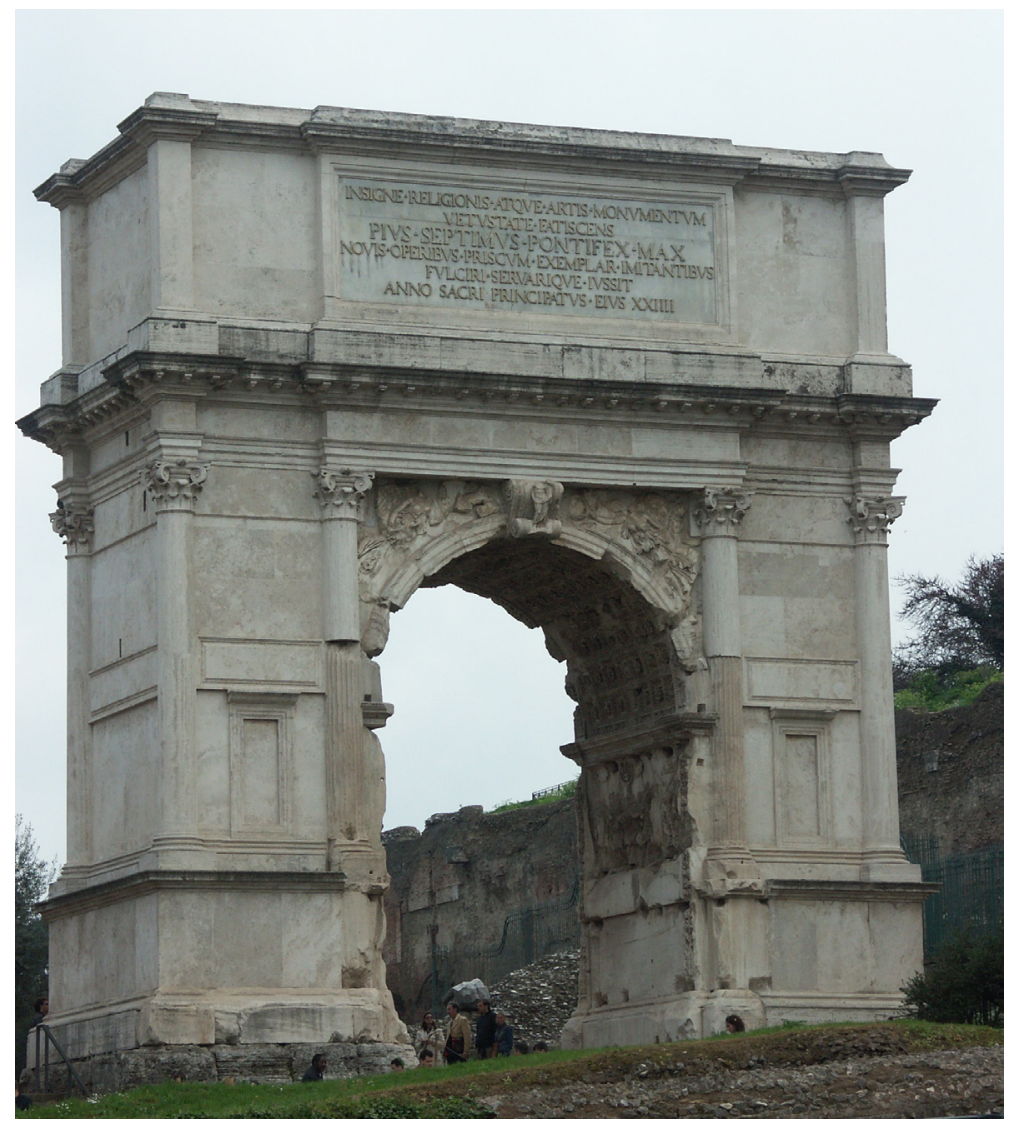

Bild 1. Titusbågen i Rom, uppförd 82 e.Kr. (foto: Mårten Snickare, Copyright CC-BY-NC-ND)

Jerusalem år 70 efter Kristus. I triumftåget längs Via Sacra färdades fältherren tillsammans med sin far kejsar Vespasianus, sina romerska soldater, judiska krigsfångar och erövrade troféer, främst bland dem menoran, den sjuarmade ljusstaken från templet i Jerusalem som lagts i ruiner. Passagen genom en triumfbåge gjorde triumfen tydlig och påtaglig samtidigt som den markerade en övergång från krigets värld till den civila världen i huvudstaden 
där Titus några år senare kom att efterträda sin far som kejsare. ${ }^{6}$ Triumftåget kan alltså förstås som en performativ handling genom vilken den romerska överheten satte punkt för kriget, upphöjde fältherren till triumfator och förödmjukade de besegrade. Det var därigenom en av många, upprepade performativa handlingar genom vilka det romerska imperiets våldsmakt manifesterades och upprätthölls. Av särskilt intresse för oss som konstvetare är att de viktigaste beståndsdelarna $\mathrm{i}$ just denna handling inte var de talade orden - även om de också spelade en framträdande roll - utan mänskliga kroppar (segrarna och deras fångar) och konstföremål (troféerna) som rörde sig genom ett arkitektoniskt artikulerat rum (triumfbågen). Avgörande för den performativa effekten var alltså vad vi idag förstår som konstvetenskapliga studieobjekt.

Förhållandet mellan Titus triumftåg och Titusbågen är inte så direkt som det i förstone kan framstå, men inte desto mindre är det avgörande för den performativa effekten. Till själva triumftåget år 7 I efter Kristus hade den romerska överheten ännu inte hunnit uppföra den permanenta triumfbåge som står där än idag utan fick nöja sig med en tillfällig konstruktion, ett slags kuliss. Den färdiga triumfbågen stod på plats först elva år senare, två år efter Titus död. Den kan därmed beskrivas som ett monument över Titus triumf, men kanske ännu hellre som ett förevigande av triumftåget, ett sätt att $\mathrm{i}$ betong och marmor hålla kvar och förlänga triumftågets performativa effekt.

Av betydelse för den kvardröjande performativa effekten är de två relieferna på triumfbågens insida som 


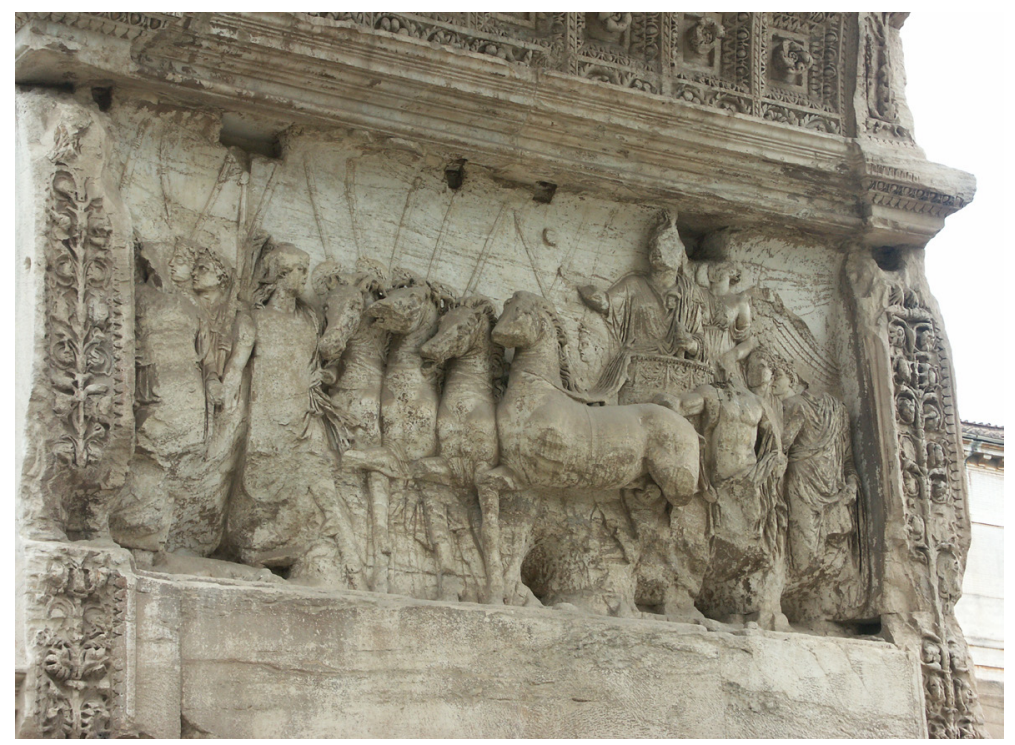

Bild 2. Reliefen på Titusbågens nordöstra sida, 82 e.Kr. (foto: Mårten Snickare, Copyright CC-BY-NC-ND)

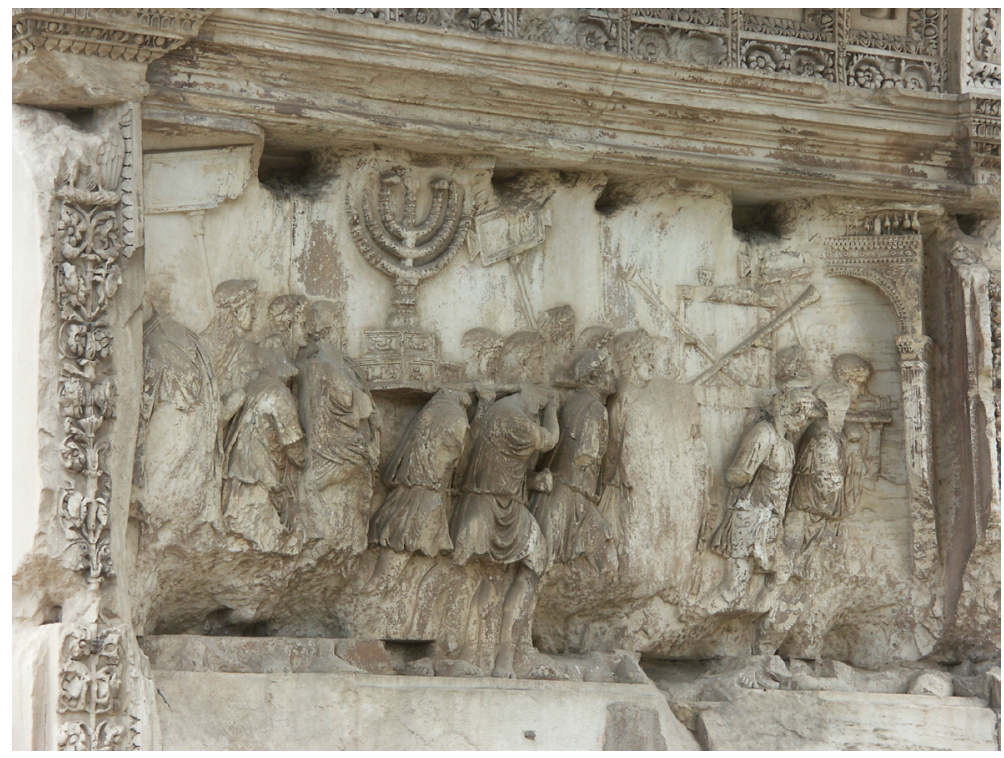

Bild 3: Reliefen på Titusbågens sydvästra sida, 82 e.Kr. (foto: Mårten Snickare, Copyright CC-BY-NC-ND) 
skildrar två av triumftågets centrala scener (bild 2 och 3). På ena sidan ses triumfatorn Titus färdas i fyrspann, på den andra romerska soldater som bär den sjuarmade ljusstaken och andra troféer. ${ }^{7}$ Där finns även några gestalter som kan definieras som judiska fångar. Den djupa reliefen som på sina håll gränsar till rundskulptur ger ett rörligt och livfullt intryck. Ljus och skugga spelar i klädedräkternas veck och detaljers inbördes relationer är beroende av betraktarens position. Känslan av liv och rörelse blir som starkast för den betraktare som passerar genom triumfbågen, förbi relieferna. Effekten kan beskrivas som att relieferna spelar upp och levandegör triumftåget på nytt varje gång en uppmärksam betraktare går genom triumfbågen och tar del av dem. Relieferna fungerar därmed både som en visuell representation av en historisk händelse och ett performativt återuppförande av denna händelse. För att återknyta till Austin kan de förstås som både konstativa och performativa beroende på sammanhanget, situationen och betraktarpositionen. Vi kan tänka oss en dräkthistoriker specialiserad på dräktskicket i kejsartidens Rom, som studerar hur dräkterna representeras i relieferna och jämför med andra visuella och skriftliga källor från tiden. En konstativ betraktarposition. Vi kan å andra sidan tänka oss en judisk besökare som blir illa berörd av reliefernas ständiga återuppförande av förödmjukelsen av de besegrade judarna och vanhelgandet av menoran, och som vägrar att gå igenom triumfbågen. En performativ betraktarposition. Faktum är att det under den nästan tvåtusenåriga historien sedan Titusbågen uppfördes betraktats som tabu för en jude att passera genom den, ett exempel på 
dess starka kvardröjande performativa kraft. Jag återkommer till det.

Titusbågen exemplifierar därmed två olika sätt på vilka konst och arkitektur kan förstås i termer av performativitet: den utgör både en betydelsebärande $d e l$ av en performativ handling och en visuell representation av samma handling. I konsthistorien finns det gott om liknande exempel. Om Nattvarden förekommer som motiv på en altartavla kan det beskrivas som en representation av den ursprungliga Nattvarden. Men samtidigt blir det ett betydelsebärande element i nattvardsriten som äger rum framför altaret. Bilden och riten samspelar och förstärker varandras innebörd och effekt.

Med utgångspunkt i begreppet performativitet framstår relationen mellan språk och verklighet som instabil och föränderlig. Vårt sätt att tala om världen påverkar världen. På ett liknande sätt går det att förstå konstverk och andra bilder, inte bara som representationer av världen utan som bildhandlingar som kan åstadkomma förändring. Claude Lorrains (ı604-82) landskapsmålningar är inte bara visuella representationer av landskap. De är bildhandlingar som fått människor att se och förstå landskap på nya sätt och som rentav lett till fysiska förändringar av landskapet: för den så kallade engelska parken som blev populär i Europa under I700-talets andra hälft var Claudes målningar en viktig inspirationskälla. Picassos (I88I-I973) Guernica (I937) är inte bara en återgivning av terrorbombningen mot den baskiska staden Gernika under spanska inbördeskriget; den är en bildhandling som bidrog till att väcka världens vrede mot fascisternas grymheter 
och som fortfarande medverkar till att forma vår förståelse av historien och den mänskliga existensen genom att i en konstnärlig gestaltning hålla fram en enskild händelse som en allmängiltig bild av grymhet och lidande.

En viktig aspekt av detta, som bland annat diskuterats och teoretiserats av den fransk-algeriska filosofen Jacques Derrida, är att performativa handlingar kan fortsätta att producera ny mening långt bortom deras upphovspersoners intentioner. ${ }^{8}$ En performativ handling kan, eller rentav måste, frigöra sig från upphovspersonens kontroll; den kan brytas loss från sin ursprungliga kontext, upprepas, citeras och infogas i oändligt många nya kontexter. Om vi återvänder till Titusbågen kan vi se hur den genom historien fungerat just så, hur den avlägsnat sig från sina upphovspersoners kontroll och fortsatt att producera ny performativ mening i nya kulturella och politiska sammanhang. Under renässansen var Rom den självklara mötesplatsen för konstnärer och arkitekter från hela Europa. Ett antikvariskt intresse för antiken växte sig allt starkare och de antika lämningarna i staden studerades i minsta detalj. Antiken, i synnerhet den romerska kejsartiden, tjänade som förebild för de framväxande europeiska nationalstaterna. Kejsartidens konst och arkitektur utgjorde en oändlig källa att ösa ur för de konstnärer och arkitekter som hade till uppgift att visuellt manifestera och legitimera nationalstaten och kungamakten. Rom utgjorde också centrum för den katolska kyrkan och säte för påveämbetet som genom hotet från reformationen i norra Europa kände allt starkare behov av slagkraftig retorik och propaganda. 
I skärningspunkten mellan dessa intressen inlemmades Titusbågen i den påvliga processionsvägen mellan Roms två viktigaste kyrkor, Peterskyrkan som är hela katolicismens huvudkyrka och Lateranbasilikan som är staden Roms domkyrka. Triumfbågen som hade rests femtonhundra år tidigare togs nu i anspråk av påvemakten. Det var inte längre en romersk fältherre som färdades i fyrspann genom den utan en påve i sin bärstol. Triumfen gällde inte längre Roms militära övermakt utan den katolska kyrkan som genom missionsverksamhet spred sitt budskap över världen. Över triumfbågens ursprungliga inskriptioner som hyllat fältherren Titus placerades nya som jämförde kejsartidens Rom med den nya påvestaden: Rom var mäktigt under sina kejsare och fältherrar men är än mäktigare under sina påvar, löd budskapet. Den här palimpsesten bär på en intressant ambivalens: å ena sidan togs antikens glans och auktoritet i anspråk i den visuella manifestationen av påvemakten, å andra sidan formulerades påvekyrkans triumf över den hedniska antiken. Den katolska kyrkan och påvemakten i Rom utgjorde en ny kontext för Titusbågen, en kontext $\mathrm{i}$ vilken triumfbågens performativa effekt blev en annan än den ursprungliga. I mitten av I 500-talet beslutade påven Paulus IV (I 476-I 559) att Roms judiska församling årligen skulle samlas vid Titusbågen för att svära påven trohet och underkastelse. ${ }^{9}$ Monumentets ursprungliga funktion som manifestation av judisk förödmjukelse och underkastelse under Rom aktualiserades därmed igen $\mathrm{i}$ en ny tid och i ett nytt religiöst, politiskt och socialt sammanhang.

Med Titusbågen som exempel blir det tydligt hur intimt sammanlänkat det performativa är med 
frågor om makt och auktoritet. Det var genom performativa tal- och bildhandlingar som det romerska kejsardömets makt, eller påvekyrkans storhet, konstruerades och legitimerades. Som både Derrida och den amerikanska filosofen Judith Butler (f. I956) framhållit kan det emellertid uppstå en glipa i den performativa handlingen, en risk - eller möjlighet att effekten inte motsvarar upphovspersonernas intentioner. ${ }^{\mathrm{IO}} \mathrm{I}$ det performativa öppnas därmed också ett utrymme för kritiska, subversiva handlingar som ifrågasätter och utmanar rådande makthierarkier. Ett intressant exempel är vad som skedde vid Titusbågen den 23 december 1997. Femtio år efter grundandet av staten Israel och på initiativ av den judiska församlingen i Rom samlades då församlingen tillsammans med judiska och italienska dignitärer till en ceremoni vid Titusbågen, med syftet att en gång för alla bryta tabut kring monumentet och att göra upp med historien av förödmjukelse och förföljelse. Italiens dåvarande premiärminister Romano Prodi drog i sitt tal paralleller mellan Titus erövring och Förintelsen och framhöll alla människors rätt att leva i fred och värdighet var som helst i världen. Roms borgmästare Francesco Rutelli talade om hur Titus och hans soldater, som representeras i triumfbågens reliefer, numera framstod som en fotnot $\mathrm{i}$ historien. De förödmjukade, tillfångatagna judarna däremot, även de skildrade i relieferna, är representanter för en kultur som fortsätter att blomstra. "Detta”, förklarade Rutelli, "är vad triumfbågen betyder för mig”. ${ }^{\text {I }}$ Därefter öppnades passagen genom Titusbågen för de medlemmar av den judiska församlingen som ville passera genom den. En del tvekade men många tog så småningom 
chansen att på detta sätt bidra till upphävandet av det tvåtusenåriga tabut. Tillsammans formade de många enskilda passagerna genom triumfbågen en kraftfull performativ handling som omförhandlade dess mening. Ett monument förknippat med förtrycket av judar kom nu också att manifestera den judiska församlingens upprättelse.

I konstvetenskaplig forskning ställs ofta frågan om ett konstverks mening. Och svaret på den frågan brukar ofta sökas i de ursprungliga intentionerna med konstverket. Ta till exempel Erwin Panofsky (1882-I968), en av I900-talets mest inflytelserika konsthistoriker. Med sin ikonologiska metod sökte han sig tillbaka till ett konstverks ursprungliga bildprogram, den urtext som formulerats eller valts ut av beställare och konstnär. ${ }^{\mathrm{I} 2}$ Där fanns svaret på frågan om konstverkets mening. När jag här följt Titusbågen genom historien, från antiken till vår egen tid, har en delvis annorlunda förståelse av "mening" vuxit fram. Titusbågens mening har inte varit en och densamma utan gång på gång omförhandlats i samspel med människors performativa handlingar och rörelser och i relation till skiftande historiska skeenden. Jag skulle vilja kalla det här för konstverkets performativa mening, den mening som aktualiseras och spelas upp genom rörelser, gester och talhandlingar i anslutning till konstverket. Definierad på det sättet framstår ett konstverks mening som föremål för ständig förhandling och förvandling. Den är inte lika stabil som den mening som definieras utifrån konstnärens intentioner eller ett ursprungligt bildprogram. Men den performativa meningen är inte heller godtycklig. Den präglas 
och begränsas av traditionens makt, av kulturella konventioner och av betraktarnas och brukarnas kunskaper, förutfattade meningar och sociala positioner. Såhär har det formulerats av Judith Butler:

Om en performativ handling når provisorisk framgång (och jag menar att "framgång" alltid och endast är provisorisk) så är det inte på grund av att en intention framgångsrikt kontrollerar talhandlingen, utan endast därför att handlingen genljuder av tidigare handlingar, och ackumulerar deras makt genom repeterandet eller citerandet av tidigare auktoritativa praktiker. ${ }^{\mathrm{I3}}$

Jag har gett exempel på handlingar i anslutning till Titusbågen, från antiken till vår tid. En del aktörer, som fältherren Titus eller påven, har utfört handlingarna från en position av makt och auktoritet. Andra, som Roms judiska församling, har istället befunnit sig i en position av underordning. Men alla har de, utifrån sina positioner och förutsättningar, deltagit i en pågående förhandling om Titusbågens performativa mening. Och den förhandlingen har hela tiden präglats av traditionen, eller av de "tidigare handlingar” som Butler talar om.

\section{Vidare läsning}

Peter Gillgren \& Mårten Snickare (red.), Performativity and Performance in Baroque Rome, Ashgate, Farnham, 20I2.

Peter Liljenstolpe, Studies in Roman Architecture. Configuring the Classical Orders, (diss.) Uppsala Universitet, Uppsala, 2000.

J. Hillis Miller, Speech Acts in Literature, Stanford University Press, Stanford, California, 200I. 
Mårten Snickare, ”How to Do Things With Piazza San Pietro. Performativity and Baroque Architecure", i: Peter Gillgren \& Mårten Snickare (red.), Performativity and Performance in Baroque Rome, Ashgate, Farnham, 201 2, s. 65-83.

Mårten Snickare, "Performing Papal Authority. Procession as a Commonplace in I7th Century Rome", i: Cathryn Banks \& Philiep Bossier (red.), Commonplace Culture in Western Europe in the Early Modern Period, II: Consolidation of God-given Power, Groningen Studies in Cultural Change, Vol. XL, Peeters Publishers, Leuven-Paris-Walpole MA, 2OII, s. I43-I 58.

Leon Yarden, The Spoils of Jerusalem on the Arch of Titus. A Re-investigation, Svenska Institutet i Rom, Stockholm I99I.

\section{Noter}

I. J. L. Austin, How to Do Things with Words, Harvard University Press, London, 1962. Det begrepp Austin använder är "speech act" (se till exempel s. I46). Begreppet förekommer inte så ofta hos Austin men har genom hans efterföljare John Searle och dennes så kallade "speech act theory" fått en viktig roll. Se John R. Searle, Speech Acts: an Essay in the Philosophy of Language, Cambridge University Press, Cambridge, I969.

2. Austin I962, s. 88-89.

3. Den amerikanske litteraturvetaren och kritikern Hillis Miller (f I928) har på motsvarande sätt myntat begreppet sign acts (teckenhandlingar) för att peka ut betydelsen av ickespråkliga tecken i performativa handlingar. Se J. Hillis Miller, Speech Acts in Literature, Stanford University Press, Stanford, California, $200 \mathrm{I}$.

4. Se till exempel Frank B. Sear, Roman Architecture, Batsford, London, I982, s. 44, I45-46; Peter Liljenstolpe, 
Studies in Roman Architecture. Configuring the Classical Orders, diss. Uppsala universitet, Uppsala, 2000, s. 92; Hugh Honour \& John Fleming, A World History of Art, Macmillan, London 1982 (och fler upplagor), s. I68-69. Kompositaordningen är en kolonnordning som förenar formelement från den joniska och den korintiska kolonnordningen.

5. Sear I982, s. I45.

6. I en studie från I909 har antropologen Arnold van Gennep myntat begreppet passageriter (rites de passage) om sådana riter genom vilka en människa förs från ett stadium till en annan, såsom bröllopet eller olika mandomsriter. van Gennep diskuterar också det romerska triumftåget som en sådan passagerit från krigets värld till fredens och framhåller särskilt betydelsen av passagen genom en triumfbåge. Nästan femtio år före Austin kan man säga att van Gennep föregrep flera av hans tankar. Se Arnold van Gennep, The Rites of Passage, Routledge \& Kegan Paul, London (I909) I960.

7. En studie av troféerna har gjorts av Leon Yarden, The Spoils of Jerusalem on the Arch of Titus. A Reinvestigation, Svenska institutet i Rom, Stockholm, I99I.

8. Jacques Derrida, "Signature Event Context", Margins of Philosophy, University of Chicago Press, Chicago, I982, s. 32 I-24.

9. Richard Joseph Ingersoll, The Ritual Use of Public Space in Renaissance Rome, opublicerad avhandling, University of California, Berkeley, I985, s. I7 I-223.

IO. Derrida I982, s. 321-24; Judith Butler, Gender Trouble. Feminism and the Subversion of Identity, Routledge, New York, (I990) I999, kapitel 3, särskilt s. I74-I 80 .

I I. Morton Satin, “One Man's Campign Against the Arch of Titus - and how It Changed Italy's Jews", 
Forward, I December 2013, http://forward.com/ articles/I 88460/one-mans-campaign-against-the-archof-titus-and/? $\mathrm{p}=$ all

I2. Erwin Panofsky, Studies in Iconology: Humanistic Themes in the Art of the Renaissance, Oxford University Press, New York, 1939.

I3. Judith Butler, Bodies that Matter: on the Discursive Limits of "Sex", Routledge, New York, I993, s. 22627: "If a performative provisionally succeeds (and I will suggest that "success" is always and only provisional) then it is not because an intention successfully governs the action of speech, but only because that action echoes prior actions, and accumulates the force of authority through the repetition or citation of a prior and authoritative set of practices." 